\title{
Metastatic Profile of Newly Diagnosed Prostate Cancer Patients in Calabar, South- South Nigeria
}

Ima-Abasi E. Bassey ${ }^{1}$, Edoise M. Isiwele ${ }^{2^{*}}$

${ }^{1}$ Department of Pathology, University of Calabar, Nigeria

${ }^{2}$ Department of Urology, University of Calabar Teaching Hospital, Nigeria

\section{Article History}

Received: 22.08.2020

Accepted: 09.09.2020

Published: 23.10 .2020

Journal homepage:

https://www.easpublisher.com/easjms

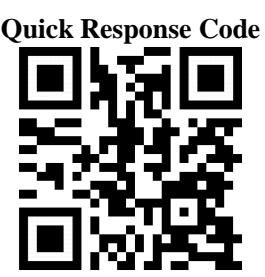

Abstract: African men tend to present late with advanced prostate cancer (CaP) making prognosis grave despite treatment. This study was carried out to document findings in patients with metastatic prostate cancer at presentation. Seventeen (17) patients with metastatic $\mathrm{CaP}$ at presentation who had complete data were recruited. Peak age group was between 51 and 70 years of age with the commonest site of metastasis being bone $(68.42 \%)$ and 2 patients $(10.52 \%)$ having multiple sites of metastasis. The PSA range was 5.5-140 $\mathrm{ng} / \mathrm{ml}$ with most patients having values above $20 \mathrm{ng} / \mathrm{ml}$ and most patients were found to be within the higher prognostic grade groups. Metastatic prostate cancer is a challenge in our setting and there is need for routine screening for this disease.

Keywords: Metastasis, Prognostic Grade Group, Prostate Cancer.

Copyright (C) 2020 The Author(s): This is an open-access article distributed under the terms of the Creative Commons Attribution 4.0 International License (CC BY-NC 4.0) which permits unrestricted use, distribution, and reproduction in any medium for non-commercial use provided the original author and source are credited.

\section{INTRODUCTION}

Prostate cancer incidence and mortality rates are known to vary widely by geographical location and ethnicity, with rates believed to be influenced by genetics, culture, diet and other environmental factors $[1,2]$. Men of African descent are more likely than white men to be diagnosed with aggressive prostate cancer $(\mathrm{CaP})$ and in Africa, significantly higher proportion of men present late with advanced disease compared to most other regions of the world [3, 2, 4]. Reports from different parts of Nigeria indicate that prostate cancer is common and many patients present late with advanced and complicated disease [5-7]. In Calabar, South Southern Nigeria, prostate cancer is noted to be the most common urologic malignancy with significantly large number of patients presenting late, with advanced disease [8-11]. The principal challenge with prostate cancer is its propensity to metastasize which arises from specific molecular mechanisms and interactions leading to local invasion, extravasation and distal migration from the primary site, followed by endothelial attachment, transmigration and site-specific establishment of metastases at secondary sites [12]. This study was carried out to document findings in patients with metastatic disease among a cohort of histologically diagnosed CaP patients.

\section{MATERIAL AND METHODS}

Between January 2001 and December 2010, 111 histologically diagnosed cases of prostate cancer were recorded at the University of Calabar Teaching Hospital, Calabar. Records retrieved from their case notes, clinic and ward registers and histopathology records were studied. Patients' demographic data, histologic diagnoses including Gleason's grade groups, and PSA values were extracted and analyzed.

\section{RESULTS}

Of the 111 patients studied, $23(20.7 \%)$ had metastasis at presentation while $67(60.4 \%)$ had no evidence of metastasis (Figure 1). Out of these 23 patients, 17 had complete data and these were recruited for the study.

The peak age group was between 51 and 70 years of age with one case of metastasis each recorded in the 31-40 and 81-90 age groups (Table 1). The commonest site of metastasis was bone $(68.42 \%)$, followed by rectum $(10.52 \%)$ as seen in Figure 2 . Multiple sites of metastasis were recorded in 2 patients $(10.52 \%)$. One had metastasis to the bone and abdomen and the other to both bone and brain. The PSA range was $5.5-140 \mathrm{ng} / \mathrm{ml}$ with most patients having values above $20 \mathrm{ng} / \mathrm{ml}$ (Figure 3). Most patients were found to 
be within the higher prognostic grade groups (Groups 3 to 5) (Figure 4).

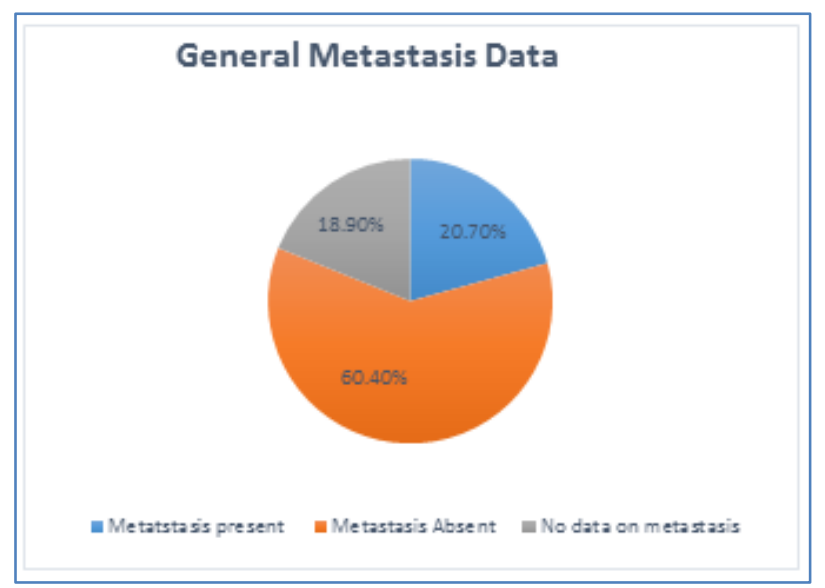

Fig-1: General metastasis data

Table-1: Age at Metastasis

\begin{tabular}{|l|l|}
\hline AGE & NO OF PATIENTS WITH METASTASIS \\
\hline $31-40$ & 1 \\
\hline $41-50$ & - \\
\hline $51-60$ & 6 \\
\hline $61-70$ & 6 \\
\hline $71-80$ & 3 \\
\hline $81-90$ & 1 \\
\hline
\end{tabular}

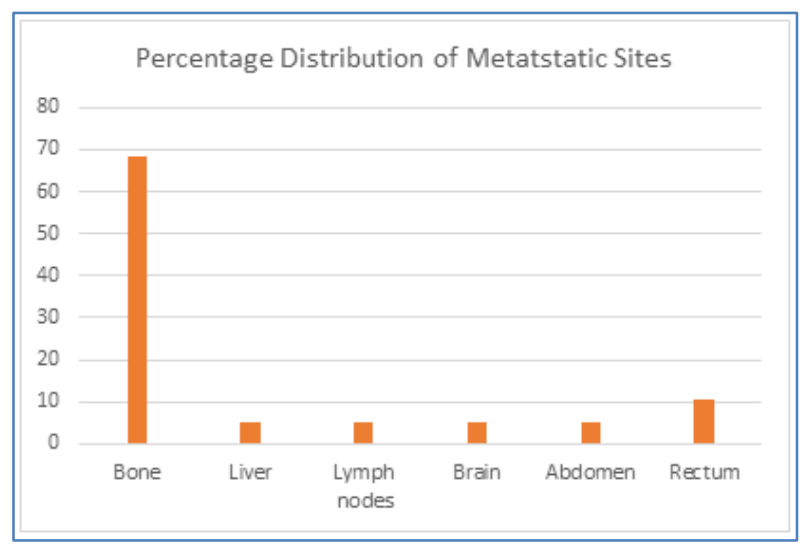

Fig-2: Distribution of Metastatic Sites

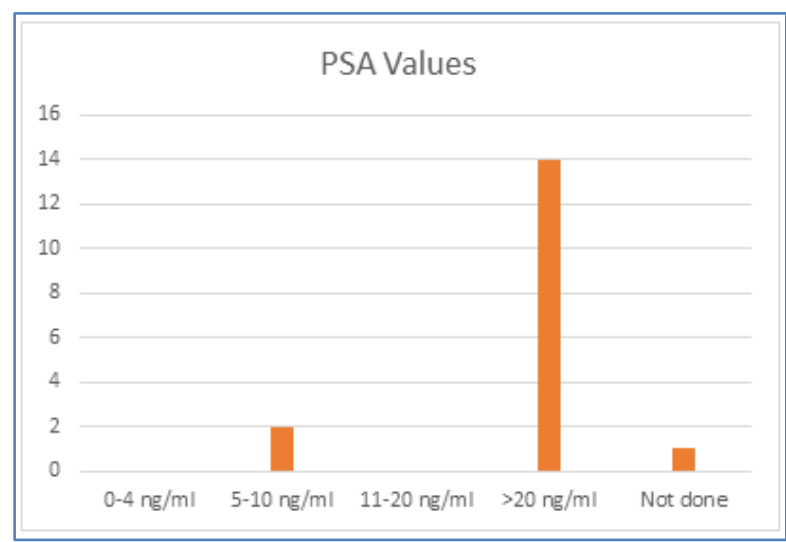

Fig-3: PSA values

\section{Prognostic Grade Group of Metastatic Disease}

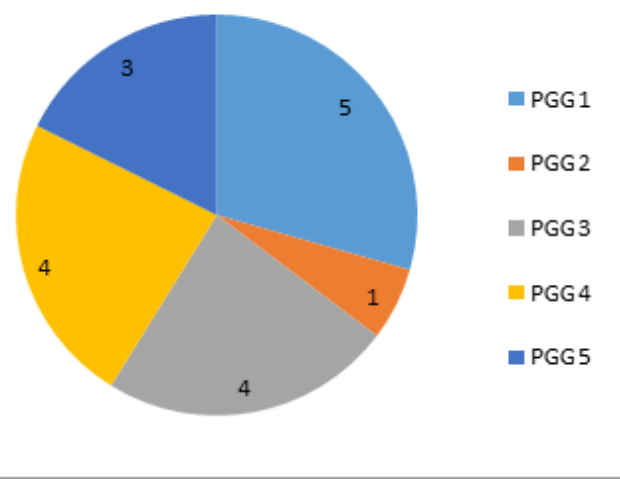

Fig-4: Prognostic grade group of metastatic disease

\section{DISCUSSION}

Prostate cancer is considered a disease of the elderly with risk increasing with advancing age. It occurs rarely in younger men and when it does it is usually an undifferentiated disease which is aggressive with resultant poor prognosis [13]. The peak age in our cohort of patients with metastasis at presentation was 51-70 years, with one patient in the age group of 31-40 years being diagnosed with metastatic disease? A previous study in Calabar had recorded more aggressive disease in the younger age group [10]. The commonest site of metastasis was to bone $(68.4 \%)$, followed by spread to rectum $(10.52 \%)$, and with spread to liver, lymph nodes, brain and abdomen noted to be $5.26 \%$ each. This is in consonance with what is known about the disease as previous studies indicate that there is bony metastasis in as high as $80 \%$ of $\mathrm{CaP}$ cases and above with attendant complications like bone pain, spinal cord compression and fractures (pathologic/ nonpathologic) [14-16]. The reasons for its predilection to metastasize to bones as well as the exact mechanisms of metastasis are not known but however believed to be due to tumour biology $[16,17]$. Theories put forward include the "seed and soil" hypothesis as well as the homing theory $[14,18,19]$. Metastasis to visceral sites is less common and is mostly to the lungs and liver but more importantly signifies a graver prognosis [20-23]. Most of our patients had PSA values greater than 20 $\mathrm{ng} / \mathrm{ml}$. Very high PSA values are indicative of more advanced disease with associated worse prognosis which was seen in our study. Even though this is the norm, certain patients have been noted to develop metastatic $\mathrm{CaP}$ at low PSAs. PSAs as low as $0.02 \mathrm{ng} / \mathrm{ml}$ have been recorded in such patients and they are noted to have undifferentiated and very aggressive disease $[24,25,26]$ Iwamoto and colleagues [27] in their study from 2000-2014 on 1873 patients had concluded that PSA is a useful biomarker for predicting prognosis at levels between 20 and $70 \mathrm{ng} / \mathrm{ml}$. While Gleason's score is the single most important predictor of prostate cancer prognosis, the new grading system, known as the Grade 
Grouping System, better classifies CaP [28]. It is a fivetiered grading system with a higher prognostic discrimination than the most commonly used combinations of the Gleason score which has been accepted by the World Health Organization and the International Society of Urological Pathology [29-31]. Most (11) of our patients $(64.70 \%)$ were within Gleason grade groups 3-5 indicating more advanced disease with poorer prognosis. The difference in Grade Groups is especially critical for selecting a therapy and has the potential to substantially reduce overtreatment of lowrisk tumors. In the new system, the Gleason score 6 corresponds to the Grade Group 1, in which are typically tumors with the lowest grade possible on needle biopsy. In this case, treatment options, such as radical prostatectomy or radiotherapy, would be considered an over-treatment for most men because of the indolent nature of the disease. An older man with Grade Group 1 cancer will benefit better from active surveillance (after proper consideration of the clinical condition and other relevant parameters like the clinical stage and PSA level) than radiotherapy or surgery, which may be accompanied with significant side effects like erectile dysfunction or incontinence. Meanwhile, a younger man will require closer follow-up to evaluate pertinent treatments, because he may be prone to develop more aggressive cancer later on in life. The original Gleason system typically considers Gleason score 7 as requiring radiation therapy. However, in the new system Gleason score 7 has been split up into Grade Group 2 (Grade 3+4) and Grade Group 3 (Grade $4+3$ ), in which Grade Group 3's prognosis is twice as bad as Grade Group 2's. The management for Grade Group 3 includes hormonal therapy in addition to radiation/ radical prostatectomy, which carries significant side effects, whereas Grade Group 2 is treated with radiation/ radical prostatectomy and subsequent follow up. Similarly, the Gleason scores 810 were typically considered one grade in terms of management, yet in the new grading system, these grades have been split into Grade Group 4 and Grade Group 5, where again the latter is twice as aggressive as the former [32, 33, 28]. A greater percentage of men will receive a more appropriate treatment now than they would have had, using the most common combinations of the Gleason score.

\section{CONCLUSION}

Metastatic prostate cancer is a challenge in our setting with its attendant complications. Early diagnosis remains key in the management of this common disease bringing to the fore, once again, the need for routine screening for the disease.

\section{REFERENCES}

1. Reddy, S., Shapiro, M., Morton, R., \& Brawley, O. W. (2003). Prostate cancer in black and white Americans. Cancer and metastasis Reviews, 22(1), 83-86.

2. Zeigler-Johnson, C. M., Rennert, H., Mittal, R. D.,
Jalloh, M., Sachdeva, R., Malkowicz, S. B., ... \& Rebbeck, T. R. (2008). Evaluation of prostate cancer characteristics in four populations worldwide. The Canadian journal of urology, 15(3), 4056.

3. Cassell, A., Yunusa, B., Jalloh, M., Ndoye, M., Mbodji, M. M., Diallo, A., ... \& Gueye, S. M. (2019). Management of advanced and metastatic prostate cancer: a need for a Sub-Saharan guideline. Journal of Oncology, 2019.

4. Bello, J. O. (2017). Predictors of survival outcomes in native sub Saharan black men newly diagnosed with metastatic prostate cancer. BMC urology, 17(1), 39.

5. Yawe, K. T., Tahir, M. B., \& Nggada, H. A. (2006). Prostate cancer in Maiduguri. West African journal of medicine, 25(4), 298.

6. Dawam, D., Rafindadi, A. H., \& Kalayi, G. D. (2000). Benign prostatic hyperplasia and prostate carcinoma in native Africans. BJU international, 85(9), 1074-1077.

7. Badmus, T. A., Adesunkanmi, A. R. K., Yusuf, B. M., Oseni, G. O., Eziyi, A. K., Bakare, T. I., ... \& Badmus, S. A. (2010). Burden of prostate cancer in southwestern Nigeria. Urology, 76(2), 412-416.

8. Ekwere, P. D., \& Egbe, S. N. (2002). The changing pattern of prostate cancer in Nigerians: current status in the southeastern states. Journal of the National Medical association, 94(7), 619.

9. Isiwele, E. M., Bassey, I. A. E., Ikpi, E. E., Enakirerhi, G. E., Otobo, F. O., Essiet, A., \& Ekwere, P. D. (2018). Histopathologic Patterns of Urological Malignancies in Calabar, SouthSouthern Nigeria: A Ten-Year Review. Journal of Cancer and Tumor International, 1-10.

10. Bassey, Ima-Abasi, E., Edoise, M. I, \& Ayi, D. (2018). Prognostication Studies of Prostate Cancer in Black Africa: Findings from Calabar, SouthSouth Nigeria. Int J Cont Med Res 5 (5): E1-5.

11. Isiwele, E.M., Akanimo, E., \& Godstime, I.I. (2018). Correlation of Digital Rectal Examination Findings with Findings on Histopathology of the Prostate in Patients with Suspected Prostate Cancer Section : Urology. Int J Cont Med Res, 5(7): 12-16.

12. Clarke, N.W., Claire, A., Hart, \& Mick, D.B. (2009). Molecular Mechanisms of Metastasis in Prostate Cancer. Asian J Androl 11: 57-67. https://doi.org/10.1038/aja.2008.29.

13. Gupta, S., Gupta, A., Saini, A. K., Majumder, K., Sinha, K., \& Chahal, A. (2015). Prostate Cancer: How Young is too Young?. Current Urology, 9(4), 212-215.

14. Gandaglia, G., Abdollah, F., Schiffmann, J., Trudeau, V., Shariat, S. F., Kim, S. P., ... \& Karakiewicz, P. I. (2014). Distribution of metastatic sites in patients with prostate cancer: a population-based analysis. The Prostate, 74(2), 210-216.

15. Saad, F., Gleason, D. M., Murray, R., Tchekmedyian, S., Venner, P., Lacombe, L., ... \& 
Chen, B. (2002). A randomized, placebo-controlled trial of zoledronic acid in patients with hormonerefractory metastatic prostate carcinoma. Journal of the National Cancer Institute, 94(19), 1458-1468.

16. Arya, M., Bott, S. R., Shergill, I. S., Ahmed, H. U., Williamson, M., \& Patel, H. R. (2006). The metastatic cascade in prostate cancer. Surgical oncology, 15(3), 117-128.

17. Bubendorf, L., Schöpfer, A., Wagner, U., Sauter, G., Moch, H., Willi, N., ... \& Mihatsch, M. J. (2000). Metastatic patterns of prostate cancer: an autopsy study of 1,589 patients. Human pathology, 31(5), 578-583.

18. Paget, S. (1989). The Distribution of Secondary Growths in Cancer of the Breast. 1889. Cancer Metastasis Rev 8 (2): 98-101.

19. Jacob, K., Webber, M., Benayahu, D., \& Kleinman, H. K. (1999). Osteonectin promotes prostate cancer cell migration and invasion: a possible mechanism for metastasis to bone. Cancer research, 59(17), 4453-4457.

20. Fizazi, K., Massard, C., Smith, M. R., Rader, M. E., Brown, J. E., Milecki, P., ... \& Damião, R. (2012). Baseline covariates impacting overall survival (OS) in a phase III study of men with bone metastases from castration-resistant prostate cancer.

21. Drake, C. G. (2014). Visceral metastases and prostate cancer treatment:'die hard,' 'tough neighborhoods,'or 'evil humors'?. Oncology (Williston Park, NY), 28(11), 974.

22. Pezaro, C. J., Omlin, A., Lorente, D., Rodrigues, D. N., Ferraldeschi, R., Bianchini, D., ... \& Tunariu, N. (2014). Visceral disease in castration-resistant prostate cancer. European urology, 65(2), 270-273.

23. Budnik, J., Suri, J., Bates, J. E., Bylund, K. C., \& Milano, M. T. (2019). Prognostic significance of sites of visceral metastatic disease in prostate cancer: A population-based study of 12,180 patients. Clinical genitourinary cancer, 17(4), 260267.

24. Lee, D. K., Park, J. H., Kim, J. H., Lee, S. J., Jo, M. K., Gil, M. C., ... \& Park, J. W. (2010). Progression of prostate cancer despite an extremely low serum level of prostate-specific antigen. Korean journal of urology, 51(5), 358-361.

25. Leibovici, D., Spiess, P. E., Agarwal, P. K., Tu, S. M., Pettaway, C. A., Hitzhusen, K., ... \& Pisters, L.
L. (2007). Prostate cancer progression in the presence of undetectable or low serum prostatespecific antigen level. Cancer, 109(2), 198-204.

26. Yamamoto, S., Ito, T., Akiyama, A., Aizawa, T., Miki, M., \& Tachibana, M. (2001). M1 prostate cancer with a serum level of prostate-specific antigen less than $10 \mathrm{ng} / \mathrm{mL}$. International Journal of Urology, 8(7), 374-379.

27. Iwamoto, H., Izumi, K., Kadono, Y., \& Mizokami, A. (2019). Prognosis of patients with prostate cancer and middle range prostate-specific antigen levels of 20-100 $\mathrm{ng} / \mathrm{mL}$. International braz $j$ urol, 45(1), 61-67.

28. Epstein, J. I., Egevad, L., Amin, M. B., Delahunt, B., Srigley, J. R., \& Humphrey, P. A. (2016). The 2014 International Society of Urological Pathology (ISUP) consensus conference on Gleason grading of prostatic carcinoma. The American journal of surgical pathology, 40(2), 244-252.

29. Epstein, J. I., Zelefsky, M. J., Sjoberg, D. D., Nelson, J. B., Egevad, L., Magi-Galluzzi, C., ... \& Eastham, J. A. (2016). A contemporary prostate cancer grading system: a validated alternative to the Gleason score. European urology, 69(3), 428435.

30. Humphrey, P. A., Moch, H., Cubilla, A. L., Ulbright, T. M., \& Reuter, V. E. (2016). The 2016 WHO classification of tumours of the urinary system and male genital organs - part B: prostate and bladder tumours. European urology, 70(1), 106-119.

31. Amin, M., Boccon-Gibod, L., Egevad, L., Epstein, J. I., Humphrey, P. A., Mikuz, G., ... \& Wheeler, T. M. (2005). Prognostic and predictive factors and reporting of prostate carcinoma in prostate needle biopsy specimens. Scandinavian Journal of Urology and Nephrology, 39(sup216), 20-33.

32. Barakzai, M. A. (2019). Prostatic adenocarcinoma: A grading from Gleason to the new grade-group system: a historical and critical review. Asian Pacific journal of cancer prevention: APJCP, 20(3), 661.

33. Pierorazio, P. M., Walsh, P. C., Partin, A. W., \& Epstein, J. I. (2013). Prognostic G leason grade grouping: data based on the modified $G$ leason scoring system. BJU international,111(5), 753 760. 